\title{
O ENSINO DA SEGURANÇA CONTRA INCÊNDIO EM CURSO DE ARQUITETURA NO BRASIL
}

\section{THE TEACHING OF FIRE SAFETY IN AN ARCHITECTURE COURSE IN $B R A Z I L$}

\author{
Marcela Falcão Braga ${ }^{1}$ \\ Universidade de Brasília, Brasília, DF, Brasil, arquitetamarcelafalcao@gmail.com \\ Ivan Manoel Rezende do Valle ${ }^{2}$ \\ Universidade de Brasília, Brasília, DF, Brasil, vallefau@unb.br \\ Cláudia Maria Miranda Alencar Rocha ${ }^{3}$ \\ Universidade Federal do Tocantins, Palmas, Tocantins, Brasil, cmmalencar@gmail.com
}

\begin{abstract}
Resumo
O arquiteto precisa lidar, nas suas atribuições profissionais, com as medidas de Segurança Contra Incêndio ( $\mathrm{SCI})$ no projeto das edificações, sendo imprescindível uma sólida formação sobre esse assunto. No entanto, ainda é frágil a participação desses profissionais no processo de inserção dessas medidas na concepção do projeto, devido à deficiência no ensino dos cursos de Arquitetura e Urbanismo do Brasil. Por isso, cabe às instituições de ensino garantir o acesso a esse tema em sua grade curricular, para que o arquiteto tenha, em sua formação, noções de segurança contra incêndio suficientes para conceber um projeto arquitetônico otimizado. O objetivo do presente artigo é avaliar o ensino de $\mathrm{SCl}$ em um curso de Arquitetura e Urbanismo do Brasil. A investigação da situação do ensino dessa instituição foi realizada por meio da análise do projeto pedagógico do curso, dos planos das disciplinas e de trabalhos de conclusão de curso concebidos por alunos. Os resultados confirmaram a deficiência no ensino expressa na não existência de uma disciplina específica de $\mathrm{SCl}$, nem tão pouco abordagens e referências sobre o tema nas disciplinas de projeto. A análise dos trabalhos de conclusão de curso identificou que os erros mais recorrentes de $\mathrm{SCl}$ nos projetos são aqueles ligados às instalações prediais e à implantação dos edifícios. Espera-se que o resultado deste estudo promova reflexões para mudanças nos programas pedagógicos de cursos de graduação em Arquitetura e Urbanismo das Instituições de Ensino Superior brasileiras e que, consequentemente, contribua para o desenvolvimento profissional e para a maior segurança das edificações.
\end{abstract}

Palavras-chave: Segurança Contra Incêndio. Ensino. Projeto arquitetônico.

\begin{abstract}
In his professional assignments, the architect has to deal with the design of Fire Safety measures in buildings, being essential solid learning on this subject. However, the participation of these professionals in the process of adding these measures in the project development is still fragile, due to the fault in Architecture and Urbanism courses in Brazil. Therefore, it is the educational institutions' responsibility to guarantee access to this theme in their curriculum, so that the architect acquires, in his learning process, enough fire safety notions to design an optimized architectural project. The objective of this article is to evaluate the teaching of Fire Safety in an Architecture and Urbanism course in Brazil. The results confirmed the deficiency in teaching expressed in the absence of a specific fire safety discipline, nor approaches and references on the subject in the design classes. The analysis of the course conclusion works identified that the most recurrent errors of fire safety in the projects are those related to building installations and the implantation of buildings. We expect that the result of this study will promote reflections on changes in the pedagogical programs of Architecture and Urbanism undergraduate courses of Brazilian universities and, consequently, contribute to the professional development and to greater security of buildings.
\end{abstract}

Keywords: Fire Safety. Teaching. Architectural design.

How to cite this article:

BRAGA, Marcela Falcão; VALLE, Ivan Manoel Rezende do; ROCHA, Cláudia Maria Miranda Alencar. O ensino da segurança contra incêndio em curso de arquitetura no Brasil. PARC Pesquisa em Arquitetura e Construção, Campinas, SP, v. 11, p. e020006, 15 mai 2020. ISSN 1980-6809. DOI: https://doi.org/10.20396/parc.v11i0.8650245 


\section{Introdução}

Ao desenvolver um projeto arquitetônico, o arquiteto deve garantir a inclusão de medidas passivas de Segurança Contra Incêndio $(\mathrm{SCl})$ na sua proposta. Porém, apesar do avanço dessa temática, por meio da formulação de leis, normas e regulamentos em todo o país, é comum constatar projetos de arquitetura carentes neste quesito (ONO; SILVA; VARGAS, 2010).

Sem a compreensão das exigências de $\mathrm{SCl}$, o arquiteto não possui instrumentos para sugerir soluções de projeto eficazes, que sejam mais efetivas à segurança de seus ocupantes, do edifício e do seu entorno. Logo, é necessário que o profissional tenha, em sua formação acadêmica, disciplinas que abordem teoria, prática, interface e tecnologias de $\mathrm{SCl}$ que o permita conceber um projeto arquitetônico eficiente à segurança. Por isso, cabe às instituições de ensino superior (IES) garantir o acesso a esse tema em sua grade curricular.

Seito et al. (2008, p. 10) falam sobre o risco em formar profissionais com deficiências em $\mathrm{SCl}$ :

Os profissionais com essas deficiências em suas formações são aqueles que projetarão, construirão e aprovarão os projetos, gerando um perigo latente em $\mathrm{SCl}$ em todas as cidades.

A carência do conteúdo na formação profissional se evidenciou de tal maneira que, em 30 de março de 2017, foi sancionada a Lei Federal $n^{a} 13.425$ (BRASIL, 2017), instituindo, entre outras normativas, que os cursos de engenharia e arquitetura no Brasil incorporem temas de $\mathrm{SCl}$ em disciplinas de suas grades curriculares. A criação dessa lei demonstra a urgência em garantir o ensino da $\mathrm{SCl}$ nos cursos de Arquitetura do Brasil, para coibir a negligência das IES, mesmo existindo há anos normas técnicas da ABNT e regulamentos estaduais e municipais específicos para o projeto de segurança contra incêndio de edificações.

O Curso de Arquitetura e Urbanismo (AU) da Instituição em questão foi criado no ano de 1993 e seu atual Projeto Pedagógico do Curso (PPC) foi implantado no semestre letivo 2012/2, com carga horária total de 3.690 horas. Possui cinquenta disciplinas obrigatórias e vinte e cinco optativas.

O estudo em questão procurou detectar se o tema da $\mathrm{SCl}$ é abordado de modo satisfatório no curso de AU da Instituição, com o objetivo de contribuir para a qualidade do ensino nos cursos de Arquitetura do Brasil, reforçando a necessidade de inserção do tema da $\mathrm{SCl}$ em suas grades curriculares.

\section{Fundamentação}

O projeto arquitetônico é um sistema complexo, formado por diversos projetos complementares, que devem estar em perfeita harmonia para que o produto final seja eficiente. Por isso, de acordo com Brentano (2015), o arquiteto deve ter conhecimento básico de todos os projetos complementares, para conseguir propor soluções de projeto eficazes, já que eles interferem diretamente na proposta arquitetônica e na funcionalidade e qualidade da edificação.

Brentano (2015) afirma ainda que a maioria dos projetos de uma edificação são realizados por profissionais diferentes e sem interação entre eles, o que costuma causar, entre outros problemas, incompatibilidade, aumento de custos e falhas nos projetos. O mesmo reforça a importância da $\mathrm{SCl}$ afirmando que: 
No modelo convencional, os projetos de uma edificação são elaborados por diferentes profissionais, em tempos diferentes, sem interação, gerando quase sempre carências estéticas, deficiências de funcionalidade, problemas de conforto ambiental, durabilidade abaixo da desejada, dificuldades na execução, desperdício de materiais, problemas na manutenção posterior e, principalmente, custos bem maiores, que, via de regra, é o principal elemento balizador do empreendimento. Considerando todas estas questões, pode-se antecipar que o projeto de segurança contra incêndio deve apresentar problemas da mesma ordem, também, pois as dificuldades na sua elaboração são grandes (BRENTANO, 2015, p. 38).

Ono (2013) demonstra a importância da arquitetura atrelada à SCI quando diz que:

\begin{abstract}
A segurança contra incêndio nas edificações começa com um bom projeto arquitetônico. A concepção das áreas de circulação, a especificação adequada dos materiais de acabamento $e$ revestimento e o posicionamento das portas e janelas podem facilitar - ou impedir - o fogo de começar e se propagar.
\end{abstract}

A preocupação relativa à $\mathrm{SCl}$ no Brasil é recente. Foi apenas no ano de 1974, imediatamente após o incêndio no Edifício Andraus, que a Prefeitura Municipal de São Paulo editou o Decreto Municipal $n^{\circ}$ 10.878, que "institui normas especiais para a segurança dos edifícios a serem observadas na elaboração do projeto, na execução, bem como no equipamento e dispõe ainda sobre sua aplicação em caráter prioritário". Em 1975, as regras estabelecidas no referido Decreto foram incorporadas na Lei $n^{\circ}$ 8.266/75, o novo Código de Edificações para o Município de São Paulo (SEITO et al., 2008, p. 25). A partir de então, os demais estados criaram suas próprias leis a fim de melhorar as condições SCI nas edificações. Segundo Brentano (2015, p. 49), essa diversidade de legislação oferece dificuldades para as atividades profissionais e para os órgãos fiscalizadores, já que as exigências mudam a cada estado.

Em todo território brasileiro as medidas de SCI podem ser classificadas como "proteção passiva" ou como "proteção ativa" (SEITO et al., 2008, p. 124). As medidas de proteção passiva são aquelas incorporadas à construção da edificação, em que seu desempenho independe de ações externas (ONO; SILVA; VARGAS, 2010). Várias destas já devem ser previstas no projeto de arquitetura. São exemplos de proteção passiva: compartimentação horizontal e vertical, previsão de saídas de emergência, controle dos materiais de revestimento e acabamento, segurança estrutural das edificações, separação entre edificações, localização da central de gás e acesso de viaturas do corpo de bombeiros.

Brentano (2015) define as medidas de proteção ativa como medidas de reação ao fogo que já esteja ocorrendo na edificação. São medidas formadas por sistemas e equipamentos para combater o fogo ou mantê-lo sob controle até a chegada de uma possível ajuda do Corpo de Bombeiros. Ono, Silva e Vargas (2010) afirmam que um sistema de proteção ativa é constituído de sistemas prediais e de brigada de incêndio.

As principais medidas de proteção ativa são: sistema de detecção e alarme de incêndio, de iluminação de emergência, de controle de fumaça de incêndio, de extintores de incêndio, de hidrantes, de chuveiros automáticos, de espuma mecânica, de gases limpos ou $\mathrm{CO}_{2}$ e brigada de incêndio.

Embora sejam medidas classificadas como ativas, Braga (2018) afirma que algumas características do sistema de hidrantes e do sistema de chuveiros automáticos devem ser pensadas ainda na elaboração do projeto arquitetônico, como por exemplo a localização da reserva técnica de incêndio e da casa de bombas. Elas influenciam a 
concepção arquitetônica, uma vez que podem interferir na volumetria da edificação e na carga exercida na estrutura, caso seja localizada interna à edificação, ou podem causar impacto visual, principalmente quando localizadas fora da edificação. Por isso, o arquiteto deve ter conhecimento desses elementos, de modo que ao definir um reservatório de água e sua localização, o faça de maneira correta e adequada à plástica do edifício, não sendo necessário posteriormente alterar o projeto em função dos projetistas das instalações hidráulicas, por exemplo.

Integrar arquitetura e os demais sistemas de uma construção é uma demanda primordial que ganhou como aliado, nos últimos anos, a plataforma BIM (Building Information Modeling). Esta tecnologia permite simular virtualmente uma construção, gerando um modelo contendo a geometria exata dos elementos e os dados relevantes necessários para dar suporte à construção, à fabricação e ao fornecimento de insumos necessários para a realização da construção (EASTMAN, 2014).

Um estudo sobre o uso da plataforma BIM como auxiliar na verificação do atendimento da legislação de SCl em projetos arquitetônicos foi realizado por Kater e Ruschel (2014). Eles avaliaram a aplicabilidade desta ferramenta em um projeto de uma edificação residencial multifamiliar para o estado de São Paulo, que mostrou grande potencial, exceto pelo despreparo e desconhecimento da ferramenta BIM pelos profissionais envolvidos.

\section{O ensino da segurança contra incêndio nas escolas de Arquitetura e Urbanismo}

Brentano (2015) reforça que desenvolver arquitetura de edifícios associada à SCl está longe de ser algo espontâneo ou cultural, afinal até hoje os requisitos de segurança são vistos como uma exigência legal e de fiscalização, resultando em soluções arquitetônicas inseguras. Negrisolo (2011) e Seito et al. (2008) atestam que o problema se inicia na formação profissional dos projetistas de engenharia e arquitetura.

Negrisolo (2011) investigou 64 faculdades brasileiras por meio de um questionário sobre o ensino da $\mathrm{SCl}$ para alunos de arquitetura. A partir dos resultados dessa pesquisa, foi possível observar que o ensino da $\mathrm{SCl}$ não é satisfatório na maior parte dos cursos de arquitetura no Brasil. Por fim, ele conclui que:

"Essas deficiências (no ensino), se refletem no desempenho profissional, com os arquitetos e urbanistas atestando que saem para o mercado de trabalho despreparados para lidar com o tema" (NEGRISOLO, 2011, p.118).

Por isso, as instituições de ensino têm um papel fundamental na formação do profissional.

A Lei Federal 13.425/17 (BRASIL, 2017), estabelece diretrizes gerais sobre medidas de prevenção e combate a incêndio e a desastres em estabelecimentos, edificações e áreas de reunião de público. A respeito da formação dos arquitetos, a lei traz o seguinte artigo:

Art. $8^{\circ}$ Os cursos de graduação em Engenharia e Arquitetura em funcionamento no País, em universidades e organizações de ensino públicas e privadas, bem como os cursos de tecnologia e de ensino médio correlatos, incluirão nas disciplinas ministradas conteúdo relativo à prevenção e ao combate a incêndio e a desastres.

Parágrafo único. Os responsáveis pelos cursos referidos no caput deste artigo terão o prazo de seis meses, contados da entrada em vigor desta Lei, para promover as complementações necessárias no conteúdo das disciplinas ministradas, visando a atender o disposto no caput deste artigo. (BRASIL, 2017). 
De acordo com a Lei, os cursos de graduação em Arquitetura deveriam ter incluído as medidas de SCI nas disciplinas ministradas desde o dia 30 de setembro de 2017.

\section{Método}

Na primeira etapa do trabalho realizou-se pesquisa bibliográfica sobre a criação da legislação de segurança contra incêndio no Brasil, com o intuito de conhecer os fatos que influenciaram sua criação e a sua situação atual. Foi dado destaque à legislação do estado do Tocantins, que serviu de base para as análises realizadas nos Trabalhos de Conclusão de Curso (TCC), comentadas a seguir.

Ono (2007) e Brentano (2015) fundamentaram os estudos sobre a relação entre o projeto de arquitetura e a segurança contra incêndio, enquanto Negrisolo (2011) embasou a pesquisa sobre o ensino da $\mathrm{SCl}$ nas faculdades de Arquitetura do Brasil.

A percepção do ensino da $\mathrm{SCl}$ no curso de Arquitetura da Instituição foi obtida a partir das seguintes análises:

- Projeto Pedagógico do Curso (PPC);

- Planos das disciplinas de projeto de arquitetura e instalações prediais;

- TCC referentes ao segundo semestre letivo do ano de 2014 (2014.1) e ao primeiro semestre letivo do ano de 2015 (2015.1).

Os resultados de todos os estudos mencionados possibilitaram conhecer a situação atual do ensino do curso de Arquitetura dessa Instituição no quesito segurança contra incêndio.

Projeto pedagógico do curso e planos das disciplinas de projeto de arquitetura e instalações prediais

No PPC fornecido pela coordenação do curso foi analisada a existência ou não de disciplina específica obrigatória ou optativa sobre $\mathrm{SCl}$. Foram examinados também os planos de ensino das disciplinas que deveriam abordar o tema devido a sua relação direta com as questões de segurança, verificando se estas abordavam as questões de combate a incêndio, se o faziam de forma satisfatória e se traziam alguma referência bibliográfica sobre o tema. As disciplinas analisadas podem ser vistas no Quadro 1.

Quadro 1 - Disciplinas analisadas
\begin{tabular}{|c|c|c|}
\hline Período & Disciplina & $\begin{array}{c}\text { Carga } \\
\text { Horária }\end{array}$ \\
\hline $\mathbf{4}$ & Projeto de Arquitetura II & $90 \mathrm{~h}$ \\
\hline $\mathbf{5}$ & Instalações Prediais Hidrossanitárias & $60 \mathrm{~h}$ \\
\hline $\mathbf{5}$ & Projeto de Arquitetura III & $90 \mathrm{~h}$ \\
\hline $\mathbf{6}$ & Projeto de Arquitetura IV & $90 \mathrm{~h}$ \\
\hline $\mathbf{7}$ & Projeto de Arquitetura V & $90 \mathrm{~h}$ \\
\hline $\mathbf{8}$ & Projeto de Arquitetura, Urbanismo e Paisagismo Integrados & $90 \mathrm{~h}$ \\
\hline $\mathbf{1 0}$ & Trabalho de Conclusão de Curso & $330 \mathrm{~h}$ \\
\hline
\end{tabular}

Fonte: Os autores.

\section{Trabalhos de Conclusão de Curso (TCC)}

Todos os trabalhos analisados foram desenvolvidos de forma individual e aprovados por uma banca composta por três examinadores, sendo dois professores do curso de Arquitetura e Urbanismo da própria instituição de ensino e um examinador externo, definido conforme o tema do projeto. Para aprovação, o aluno não poderia tirar uma nota menor que 5,0 (cinco), em um total de 10,0 (dez) pontos. 
Tais trabalhos e suas respectivas divisões e descrições, classificadas de acordo com a Lei Estadual $n^{\circ} 1.787 / 07$ (TOCANTINS, 2007a), de 15 de maio de 2007, do estado do Tocantins, estão apresentados no Quadro 2. Tais classificações determinam as medidas de $\mathrm{SCI}$ necessárias no projeto e os seus níveis de exigência, que podem variar conforme algumas características da edificação, como a altura e sua área total construída.

\begin{tabular}{|c|c|}
\hline $\mathbf{N}$ & Divisão e Descrição \\
\hline 1 & $\begin{array}{l}\text { A3: habitação coletiva/ D1: local para prestação de serviço profissional/ E1: escola/ E2: escola } \\
\text { especial/ F1: local onde há objeto de valor inestimável }\end{array}$ \\
\hline 2 & C2: comércio/ F8: local para refeição \\
\hline 3 & E1: escola/ E2: escola especial/ F8: local para refeição \\
\hline 4 & E2: escola especial/ F1: local onde há objeto de valor inestimável \\
\hline 5 & $\begin{array}{l}\text { E4: centro de treinamento professional/ F8: local para refeição/ G2: garagem com acesso de público e } \\
\text { sem abastecimento }\end{array}$ \\
\hline 6 & $\begin{array}{l}\text { E4: centro de treinamento profissional/ F1: local onde há objeto de valor inestimável/ F5: arte cênica } \\
\text { e auditória }\end{array}$ \\
\hline 7 & E6: escolas para portadores de deficiência/ F8: local para refeição \\
\hline 8 & F1: local onde há objeto de valor inestimável/ F5: arte cênica e auditória \\
\hline 9 & $\begin{array}{l}\text { A3: habitação coletiva/ D1: local para prestação de serviço profissional/ F3: centro esportivo e de } \\
\text { exibição/ F8: local para refeição }\end{array}$ \\
\hline 10 & F8: local para refeição/ G2: garagem sem acesso público e sem abastecimento \\
\hline 11 & C2: comércio/ G3: local dotado de abastecimento de combustível/ F8: local para refeição \\
\hline 12 & G2: garagem com acesso de público e sem abastecimento/ H3: hospital e assemelhado \\
\hline 13 & $\begin{array}{l}\text { B1: hotel/ F3: centro esportivo e de exibição/ F8: local para refeição/ G2: garagem com acesso de } \\
\text { público e sem abastecimento }\end{array}$ \\
\hline 14 & $\begin{array}{l}\text { D1: local para prestação de serviço profissional/ E2: escola especial/ F3: centro esportivo e de } \\
\text { exibição/ F5: arte cênica e auditória }\end{array}$ \\
\hline 15 & $\begin{array}{l}\text { E1: escola em geral/ F1: local onde há objeto de valor inestimável/ F3: centro esportivo e de exibição/ } \\
\text { F5: arte cênica e auditória/ F8: local para refeição }\end{array}$ \\
\hline 16 & F1: local onde há objeto de valor inestimável/ F5: arte cênica e auditória \\
\hline 17 & $\begin{array}{l}\text { C2: comércio/ D1: local para prestação de serviço profissional/ F3: centro esportivo e de exibição/ H6: } \\
\text { clínica }\end{array}$ \\
\hline 18 & $\begin{array}{l}\text { A3: habitação coletiva/ F3: centro esportivo e de exibição/ F5: arte cênica e auditória/ F8: local para } \\
\text { refeição }\end{array}$ \\
\hline 19 & F6: clube social e diversão \\
\hline 20 & F5: arte cênica e auditória/ H4: repartição pública, edificações das forças armadas e policiais \\
\hline
\end{tabular}

Fonte: Os autores.

As análises realizadas nesses trabalhos foram embasadas em quatro medidas de segurança contra incêndio, de acordo com as leis do estado de Tocantins: Acesso de viaturas (TOCANTINS, 2007b), Saídas de emergência (TOCANTINS, 2007c), Sistema de Hidrantes (TOCANTINS, 2007d) e Central de Gás (TOCANTINS, 2007e). Essas medidas foram escolhidas em razão da necessidade de serem previstas ainda durante a concepção do projeto e por serem exigidas na maioria dos projetos selecionados, devido à classificação e altura dos edifícios propostos.

Duas outras leis foram consultadas devido às especificidades de alguns projetos: Recintos Esportivos (TOCANTINS, 2007f) e Cobertura de Sapé, Piaçava e Similares (TOCANTINS, 2007g). Com a lei de recintos esportivos, verificou-se as saídas de emergência, exclusivas desses espaços, enquanto que a lei de cobertura de sapé, piaçava e similares foi utilizada nos trabalhos que apresentaram a palha ou piaçava como cobertura.

A lei 04: Acesso de viaturas (TOCANTINS, 2007b) diz respeito ao acesso de viaturas do corpo de bombeiros na edificação. Braga (2018, p. 36) esclarece a importância deste acesso: 
Em caso de incêndio, a viatura do Corpo de Bombeiros pode atenuar ou extinguir o fogo por tempo suficiente para que aconteça a desocupação do edifício e a fuga segura dos ocupantes. Por isso, é necessário que a viatura se aproxime do edifício a uma distância satisfatória.

Nem todas as edificações precisam de acesso de viaturas internamente ao terreno, por isso a lei apresenta os critérios e exigências, informando a localização adequada para o estacionamento da viatura e suas medidas, bem como as dimensões do acesso. O que define a necessidade do acesso é a implantação do edifício no terreno, pois a distância entre o edifício e o meio fio influencia na proximidade da viatura. Nos casos onde o acesso é necessário, o projetista deve estar atento às suas características, pois estas podem interferir na concepção do edifício:

Então, o arquiteto deve propor a implantação consciente de sua escolha, sabendo que o acesso de viaturas possui características que influenciam a fachada, os acessos, a circulação e as áreas do entorno do edifício (BRAGA, 2018, p. 37).

Para avaliar este quesito foram selecionados projetos onde haveria a necessidade do acesso e se o mesmo foi proposto de forma correta. Ou seja, verificou-se a adequação às dimensões do portão de entrada, da via e do estacionamento da viatura.

A lei 08: Saídas de emergência (TOCANTINS, 2007C) traz as características das saídas de emergência, que são responsáveis por auxiliar o abandono seguro dos ocupantes do edifício em caso de sinistro. Compreendem acessos, portas, escadas ou rampas e corredores. Por estarem incorporadas à edificação, é necessário que o arquiteto pense nos fluxos, nos percursos e nas ligações entre ambientes e pavimentos, para então propor soluções efetivas à segurança do edifício. Além da funcionalidade, o profissional deve pensar na questão estética, já que as saídas são indispensáveis e devem ser tratadas como importantes aliadas à questão formal, ou à plástica do projeto.

Os seguintes componentes das saídas de emergência foram analisados nos projetos:

- Sentido de abertura, largura e a quantidade de portas de saída de emergência;

- Dimensionamento e declividade das rampas;

- Quantidade, tipo e largura das escadas;

- Largura dos corredores.

A lei 17: Sistema de hidrantes (TOCANTINS, 2007d) trata do sistema de hidrantes. $\mathrm{Na}$ análise foi averiguado se o volume destinado a reserva técnica de incêndio (RTI) estava correto, assim como as dimensões e localização da casa de bombas.

A Central de Gás, conforme a lei 23: Central de GLP (TOCANTINS, 2007e), deve ser prevista em locais que armazenem, para consumo próprio, mais de cinco recipientes transportáveis de Gás Liquefeito de Petróleo (GLP) de 13 kg, ou um recipiente maior que $13 \mathrm{~kg}$. Deve ser pensada de modo que seja efetiva à segurança e à função do edifício, mas que ao mesmo tempo não interfira em sua plástica. $\mathrm{Na}$ análise dos trabalhos foi verificado se a central atende às principais exigências estabelecidas na lei: localização e afastamentos.

Concluído os estudos conforme Tocantins (2007a, 2007b, 2007c, 2007d, 2007e, 2007f, 2007g), os dados obtidos foram categorizados por meio de três interpretações: Atendimento às leis, como sendo Categoria 1; Comprometimento da Arquitetura, Categoria 2; Conceito de Segurança, Categoria 3. Para estabelecer uma classificação de acertos entre os projetos, adotou-se um padrão de cores, em que a cor verde significava 
uma condição positiva, a cor laranja uma condição intermediária, a cor vermelha como negativa e a cor cinza representa o não se aplica.

Para elucidar as condições indicadas pelo padrão de cores, tomamos como exemplo os casos a seguir: na Categoria 1, o aluno que acertar a inserção do acesso de viaturas no projeto, recebe a cor verde (condição positiva); o aluno que previu o acesso de viaturas no projeto, entretanto contendo erros de dimensões, seja na via de acesso, no portão de acesso ou no estacionamento da viatura, recebe a cor laranja (condição intermediária); já o aluno que não previu acesso de viatura, mas o seu projeto tinha a necessidade do acesso, recebe a cor vermelha (condição negativa).

A Categoria 1 avaliou se o aluno ao projetar atendeu às leis de segurança. A cor vermelha significava que o aluno não atendeu, indicando uma situação negativa. Na cor laranja o aluno atendeu parcialmente, ou seja, seriam necessárias adequações, traduzindo uma condição intermediária. A cor verde significa condição positiva do projeto porque o aluno atendeu à lei.

A Categoria 2 verificou se as possíveis falhas quanto à $\mathrm{SCl}$ seriam irreparáveis para arquitetura ou, se houvesse compatibilização dos projetos, ainda seria possível reformular a arquitetura sem comprometê-la. A cor verde indicou um projeto sem falhas, ou seja, correto quanto à $\mathrm{SCl}$ (situação positiva). A cor laranja caracterizou falhas leves, erros passíveis de adequação, sem comprometer gravemente o projeto (intermediária). A cor vermelha indicou falhas graves, que comprometeriam e/ou descaracterizariam a arquitetura ao serem reformuladas para atender às leis.

O conceito de segurança (Categoria 3 ) aferiu a percepção do aluno quanto às medidas de $\mathrm{SCl}$. A cor verde representava o conhecimento integral do aluno, uma vez que ele previu corretamente as medidas em seu projeto. A cor laranja demonstrava o entendimento parcial, pois as medidas previstas tinham falhas consideradas leves. A cor vermelha mostrou total desconhecimento da norma, por apresentar falhas graves ou por apresentar medidas superdimensionadas. Como exemplo, o aluno que previsse uma RTI com $20 \mathrm{~m}^{3}$, sendo que, segundo Tocantins (2007d), esse volume deveria ter $6 \mathrm{~m}^{3}$, mostra desconhecimento da norma, uma vez que reconhece a necessidade da inserção de uma RTI, mas não tem o conhecimento de como definir o seu volume. Portanto, esse aluno ficaria com a cor vermelha nesse item.

Com base nas tabelas-síntese geradas a partir das categorias de interpretações foram produzidos gráficos demonstrativos, com o intuito de verificar a situação dos projetos de arquitetura dos trabalhos de conclusão de curso relativa às normas de $\mathrm{SCl}$.

\section{Resultados e discussão}

Projeto pedagógico do curso e planos das disciplinas de projeto de arquitetura e instalações prediais

A partir da leitura do PPC do curso de Arquitetura da Instituição, verificou-se que não há disciplina específica de $\mathrm{SCl}$. A partir da análise das ementas das demais disciplinas, verificou-se que nenhuma aborda de forma satisfatória ou até mesmo não abordam de forma alguma os aspectos de segurança, sequer citando bibliografias sobre o tema.

A disciplina de instalações prediais hidrossanitárias faz referência, em sua ementa, às instalações prediais de combate a incêndio, conforme as recomendações da Associação Brasileira de Normas Técnicas (ABNT). Entretanto, o ideal seria fazer o uso da legislação local, que no caso é a lei 17 do Corpo de Bombeiros Militar do Tocantins (CBM/TO). Ainda de acordo com sua ementa, a disciplina tem como objetivo priorizar a relevância das instalações hidrossanitárias em compatibilidade com o processo de concepção do 
projeto de arquitetura que, segundo Brentano (2015), é a maneira correta de projetar. Ela prevê o uso preferencial de exercícios da disciplina de Projeto de Arquitetura II, um ponto positivo para que haja a inserção do tema nas disciplinas de projeto que, atualmente, não contemplam tal medida.

Em Projeto de Arquitetura III (PAIII), os alunos devem conceber um projeto de complexidade funcional moderada e com sobreposição de pavimentos. Os professores têm solicitado, recentemente, a elaboração de um projeto de habitação multifamiliar vertical. Neste caso, a ementa prevê a definição dos sistemas de circulação vertical e a introdução das normas de dimensionamento de circulações horizontais e verticais, com base na legislação local. Entretanto, essa cobrança se resume apenas às saídas de emergência, uma das várias medidas de $\mathrm{SCl}$ que devem ser incorporadas ao projeto.

A disciplina de Projeto de Arquitetura IV é a única disciplina que traz nas suas referências bibliográficas o tema, utilizando a ABNT NBR 9077: Saídas de emergência em edifícios (ABNT, 1993). Ela abrange só uma das várias medidas de $\mathrm{SCl}$, sem as especificações adicionais da legislação estadual, que é a NT 08: Saídas de emergência, do CBM/TO (TOCANTINS, 2007C).

\section{Análise dos Trabalhos de Conclusão de Curso}

O Trabalho de Conclusão de Curso do curso de Arquitetura e Urbanismo da Instituição estudada tem como objetivo avaliar a aptidão dos estudantes ao ingresso na vida profissional. Os alunos que escolhessem propor um projeto arquitetônico deveriam demonstrar conhecimento relativo às soluções em arquitetura com excelência, segundo o plano da disciplina. Por isso, esperava-se que os alunos concebessem um projeto arquitetônico envolvendo, no mínimo, as principais medidas de $\mathrm{SCl}$ contempladas na legislação local.

Serão apresentadas a seguir as análises realizadas nos TCC investigados. Nas Tabelas 1 , 2 e 3 identificou-se o projeto, a sua divisão conforme Tocantins (2007a) e as falhas relativas a cada norma analisada. As tabelas sintetizam as análises divididas nas três categorias já citadas.

\begin{tabular}{|c|c|c|c|c|c|c|c|c|}
\hline \multirow{2}{*}{$\mathbf{N}$} & \multirow{2}{*}{ Divisão } & \multirow{2}{*}{$\begin{array}{c}\text { NT 04: } \\
\text { Acesso de } \\
\text { Viaturas } \\
\text { (TOCANTINS, } \\
\text { 2007b) }\end{array}$} & \multicolumn{3}{|c|}{$\begin{array}{l}\text { NT 08: Saída de Emergência } \\
\text { (TOCANTINS, 2007C) }\end{array}$} & \multicolumn{2}{|c|}{$\begin{array}{l}\text { NT 17: Hidrante } \\
\text { (TOCANTINS, } \\
\text { 2007d) }\end{array}$} & \multirow{2}{*}{$\begin{array}{c}\text { NT 23: } \\
\text { Central de } \\
\text { Gás } \\
\text { (TOCANTINS, } \\
\text { 2007e) }\end{array}$} \\
\hline & & & Escadas & Portas & Corredores & $\begin{array}{l}\text { Casa de } \\
\text { máquina }\end{array}$ & RTI & \\
\hline 1 & $\begin{array}{l}\text { A-3/ D-1/E- } \\
1 / E-2 / F-1\end{array}$ & 口 & $\square$ & $\square$ & ש & 口 & ש & $\square$ \\
\hline 2 & $C-2 / F-8$ & $\square$ & $E$ & E & 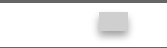 & 口 & 口 & ( \\
\hline 3 & E-2/ F-1 & $\square$ & $\square$ & 0 & ש & $\square$ & $\square$ & - \\
\hline 4 & $\begin{array}{c}\mathrm{E}-4 / \mathrm{F}-8 / \mathrm{G}- \\
2\end{array}$ & 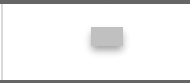 & 口 & ש & - & 口 & ש & 口 \\
\hline 5 & $\begin{array}{c}\mathrm{E}-4 / \mathrm{F}-1 / \mathrm{F}- \\
5\end{array}$ & $\square$ & 口 & $\square$ & $\square$ & $\square$ & C & $\square$ \\
\hline 6 & E-6/F-8 & 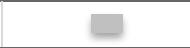 & - & 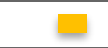 & - & E & 0 & 口 \\
\hline 7 & F-1/ F-5 & $\square$ & ש & $\square$ & $\square$ & $\square$ & $\square$ & $\square$ \\
\hline 8 & $\begin{array}{c}\text { A-3/ D-1/ F- } \\
\text { 3/F-8 }\end{array}$ & 口 & 0 & ש & ש & - & 口 & $\square$ \\
\hline 9 & F-8/ G-2 & $\square$ & $\square$ & $\square$ & 口 & E & D & $\square$ \\
\hline 10 & $\begin{array}{c}\mathrm{C}-2 / \mathrm{G}-3 / \\
\mathrm{F}-8\end{array}$ & $\square$ & 口 & 口 & ש & 口 & ש & 口 \\
\hline
\end{tabular}


BRAGA, Marcela Falcão; VALLE, Ivan Manoel Rezende do; ROCHA, Cláudia Maria Miranda Alencar

O ensino da segurança contra incêndio em curso de arquitetura no Brasil

\begin{tabular}{|c|c|c|c|c|c|c|c|c|}
\hline \multirow{2}{*}{$\mathbf{N}$} & \multirow{2}{*}{ Divisão } & \multirow{2}{*}{$\begin{array}{c}\text { NT 04: } \\
\text { Acesso de } \\
\text { Viaturas } \\
\text { (TOCANTINS, } \\
\text { 2007b) }\end{array}$} & \multicolumn{3}{|c|}{$\begin{array}{l}\text { NT 08: Saída de Emergência } \\
\text { (TOCANTINS, 2007C) }\end{array}$} & \multicolumn{2}{|c|}{$\begin{array}{l}\text { NT 17: Hidrante } \\
\text { (TOCANTINS, } \\
\text { 2007d) }\end{array}$} & \multirow{2}{*}{$\begin{array}{l}\text { NT 23: } \\
\text { Central de } \\
\text { Gás } \\
\text { (TOCANTINS, } \\
\text { 2007e) }\end{array}$} \\
\hline & & & Escadas & Portas & Corredores & $\begin{array}{l}\text { Casa de } \\
\text { máquina }\end{array}$ & RTI & \\
\hline 11 & $\begin{array}{c}E-1 / E-2 / F- \\
8\end{array}$ & ㅁ & 口 & (1) & ㅁ & 口 & 口 & 口 \\
\hline 12 & G-2/H-3 & $U$ & 口 & $\square$ & $\square$ & 口 & $\square$ & $\square$ \\
\hline 13 & $\begin{array}{c}\text { C-2/ D-1/ F- } \\
3 / \mathrm{H}-6\end{array}$ & 口 & 口 & c & 口 & 口 & 口 & - \\
\hline 14 & $\begin{array}{c}\text { B-1/ F-3/ F- } \\
8 / \mathrm{G}-2\end{array}$ & $\square$ & 口 & ㅁ & 口 & 口 & 口 & 口 \\
\hline 15 & $\begin{array}{c}\mathrm{D}-1 / \mathrm{E}-2 / \mathrm{F}- \\
3 / \mathrm{F}-5\end{array}$ & 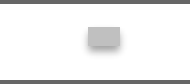 & $\square$ & $\square$ & 口 & c & 0 & - \\
\hline 16 & $\begin{array}{l}\text { E-1/ F-1/ F- } \\
\text { 3/F-5/F-8 }\end{array}$ & 0 & ש & c & c & c & (1) & 口 \\
\hline 17 & F-1/ F-5 & 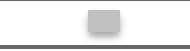 & ㅁ & ㅁ & ㅁ & ש & 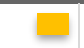 & $\square$ \\
\hline 18 & $\begin{array}{c}\text { A-3/ F-3/ F- } \\
5 / F-8\end{array}$ & - & - & $\square$ & - & C & $\sqcup$ & 口 \\
\hline 19 & $F-6$ & 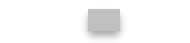 & $\square$ & 맘 & $\square$ & $\square$ & 단 & ㅁ \\
\hline 20 & F-5/H-4 & 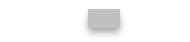 & 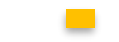 & c & (1) & $\square$ & $\square$ & 0 \\
\hline
\end{tabular}

Fonte: Os autores.

\begin{tabular}{|c|c|c|c|c|c|c|c|c|}
\hline \multirow{2}{*}{$\mathbf{N}$} & \multirow{2}{*}{ Divisão } & \multirow{2}{*}{$\begin{array}{c}\text { NT 04: } \\
\text { Acesso de } \\
\text { Viaturas } \\
\text { (TOCANTINS, } \\
\text { 2007b) }\end{array}$} & \multicolumn{3}{|c|}{$\begin{array}{l}\text { NT 08: Saída de Emergência } \\
\text { (TOCANTINS, 2007C) }\end{array}$} & \multicolumn{2}{|c|}{$\begin{array}{l}\text { NT 17: Hidrante } \\
\text { (TOCANTINS, } \\
\text { 2007d) }\end{array}$} & \multirow{2}{*}{$\begin{array}{c}\text { NT 23: } \\
\text { Central de } \\
\text { Gás } \\
\text { (TOCANTINS, } \\
\text { 2007e) }\end{array}$} \\
\hline & & & Escadas & Portas & Corredores & $\begin{array}{l}\text { Casa de } \\
\text { máquina }\end{array}$ & RTI & \\
\hline 1 & $\begin{array}{l}\text { A-3/ D-1/ E- } \\
1 / E-2 / F-1\end{array}$ & 口 & - & $\square$ & 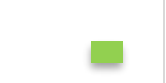 & 口 & 口 & 口 \\
\hline 2 & $C-2 / F-8$ & $\square$ & - & ㅁ & - & 口 & 口 & $\square$ \\
\hline 3 & E-2/F-1 & 口 & 口 & 단 & $\square$ & 口 & 口 & - \\
\hline 4 & $\begin{array}{c}\mathrm{E}-4 / \mathrm{F}-8 / \mathrm{G}- \\
2 \\
\end{array}$ & 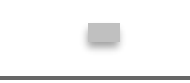 & ש & 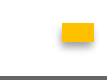 & ( & 口 & ש & $\square$ \\
\hline 5 & $\begin{array}{l}\text { E-4/ F-1/ F- } \\
5\end{array}$ & $\square$ & $\square$ & $\square$ & $\square$ & $\square$ & $\square$ & $\square$ \\
\hline 6 & E-6/F-8 & C & $\square$ & ㅁ & - & ש & ש & $\square$ \\
\hline 7 & F-1/ F-5 & 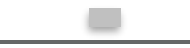 & E & E & $\square$ & 口 & 口 & $\square$ \\
\hline 8 & $\begin{array}{c}\text { A-3/ D-1/ F- } \\
\text { 3/F-8 }\end{array}$ & 口 & $\square$ & $\square$ & $\square$ & 口 & 口 & $\square$ \\
\hline 9 & F-8/ G-2 & $\square$ & $\square$ & $\square$ & $\square$ & ए & ש & $\square$ \\
\hline 10 & $\begin{array}{c}\mathrm{C}-2 / \mathrm{G}-3 / \\
\mathrm{F}-8\end{array}$ & 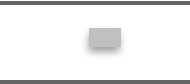 & ( & 口 & ש & 口 & 口 & - \\
\hline 11 & $\begin{array}{c}E-1 / E-2 / F- \\
8\end{array}$ & 口 & 口 & 口 & $\square$ & $\square$ & $\square$ & $\square$ \\
\hline 12 & $\mathrm{G}-2 / \mathrm{H}-3$ & $\square$ & $\square$ & 口 & 口 & 口 & $\square$ & $\square$ \\
\hline 13 & $\begin{array}{c}\text { C-2/ D-1/ F- } \\
3 / \text { H-6 }\end{array}$ & - & ש & 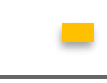 & - & 口 & 口 & - \\
\hline 14 & $\begin{array}{l}\text { B-1/ F-3/ F- } \\
8 / \text { G-2 }\end{array}$ & $\square$ & - & - & $\square$ & - & ש & - \\
\hline 15 & $\begin{array}{l}\text { D-1/ E-2/F- } \\
3 / \text { F-5 }\end{array}$ & - & $\square$ & $\square$ & 口 & $\square$ & - & - \\
\hline
\end{tabular}


BRAGA, Marcela Falcão; VALLE, Ivan Manoel Rezende do; ROCHA, Cláudia Maria Miranda Alencar

O ensino da segurança contra incêndio em curso de arquitetura no Brasil

\begin{tabular}{|c|c|c|c|c|c|c|c|c|}
\hline \multirow{2}{*}{$\mathbf{N}$} & \multirow{2}{*}{ Divisão } & \multirow{2}{*}{$\begin{array}{c}\text { NT 04: } \\
\text { Acesso de } \\
\text { Viaturas } \\
\text { (TOCANTINS, } \\
\text { 2007b) }\end{array}$} & \multicolumn{3}{|c|}{$\begin{array}{l}\text { NT 08: Saída de Emergência } \\
\text { (TOCANTINS, 2007C) }\end{array}$} & \multicolumn{2}{|c|}{$\begin{array}{l}\text { NT 17: Hidrante } \\
\text { (TOCANTINS, } \\
\text { 2007d) }\end{array}$} & \multirow{2}{*}{$\begin{array}{l}\text { NT 23: } \\
\text { Central de } \\
\text { Gás } \\
\text { (TOCANTINS, } \\
\text { 2007e) }\end{array}$} \\
\hline & & & Escadas & Portas & Corredores & $\begin{array}{l}\text { Casa de } \\
\text { máquina }\end{array}$ & RTI & \\
\hline 16 & $\begin{array}{l}\text { E-1/ F-1/ F- } \\
3 / \text { F-5/ F-8 }\end{array}$ & $\square$ & ( & - & - & E & $\square$ & ( \\
\hline 17 & F-1/ F-5 & 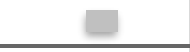 & 무 & E & $\square$ & $\square$ & 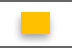 & 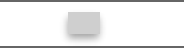 \\
\hline 18 & $\begin{array}{c}\text { A-3/F-3/F- } \\
5 / F-8\end{array}$ & 口 & U & 口 & ㅁ & - & 0 & $\square$ \\
\hline 19 & $F-6$ & $\square$ & 口 & 무․ & 0 & 분 & 단 & D \\
\hline 20 & $\mathrm{~F}-5 / \mathrm{H}-4$ & C & ㅁ & ㅁ & 口 & 口 & 口 & 口 \\
\hline
\end{tabular}

Tabela 5 - Síntese da análise da Categoria 3: Conceito de segurança

\begin{tabular}{|c|c|c|c|c|c|c|c|c|}
\hline \multirow{2}{*}{$\mathbf{N}$} & \multirow{2}{*}{ Divisão } & \multirow{2}{*}{$\begin{array}{c}\text { NT 04: } \\
\text { Acesso de } \\
\text { Viaturas } \\
\text { (TOCANTINS, } \\
\text { 2007b) }\end{array}$} & \multicolumn{3}{|c|}{$\begin{array}{l}\text { NT 08: Saída de Emergência } \\
\text { (TOCANTINS, 2007C) }\end{array}$} & \multicolumn{2}{|c|}{$\begin{array}{c}\text { NT 17: Hidrante } \\
\text { (TOCANTINS, } \\
\text { 2007d) }\end{array}$} & \multirow{2}{*}{$\begin{array}{c}\text { NT 23: } \\
\text { Central de } \\
\text { Gás } \\
\text { (TOCANTINS, } \\
\text { 2007e) }\end{array}$} \\
\hline & & & Escadas & Portas & Corredores & $\begin{array}{l}\text { Casa de } \\
\text { máquina }\end{array}$ & RTI & \\
\hline 1 & $\begin{array}{c}\text { A-3/ D-1/ } \\
\text { E-1/ E-2/ F- } \\
1\end{array}$ & & & & & & & \\
\hline 2 & $C-2 / F-8$ & $\square$ & $\square$ & $\square$ & $\square$ & $\square$ & $\square$ & $\square$ \\
\hline 3 & $E-2 / F-1$ & $\square$ & $\square$ & 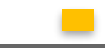 & $\square$ & $\square$ & $\square$ & $\square$ \\
\hline 4 & $\begin{array}{c}\mathrm{E}-4 / \mathrm{F}-8 / \mathrm{G}- \\
2\end{array}$ & E & $\square$ & $\square$ & $\square$ & $\square$ & - & - \\
\hline 5 & $\begin{array}{c}E-4 / F-1 / F- \\
5 \\
\end{array}$ & & & & $\square$ & & & 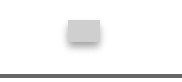 \\
\hline 6 & $E-6 / F-8$ & 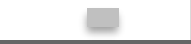 & 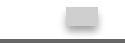 & $\square$ & - & 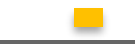 & 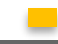 & $\square$ \\
\hline 7 & F-1/F-5 & 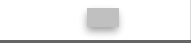 & $\square$ & $\square$ & $\square$ & - & $\square$ & $\square$ \\
\hline 8 & $\begin{array}{l}\text { A-3/ D-1/ } \\
F-3 / F-8\end{array}$ & & & & & & & \\
\hline 9 & $F-8 / G-2$ & $\square$ & $\square$ & $\square$ & $\square$ & $\square$ & L & 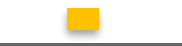 \\
\hline 10 & $\begin{array}{c}\mathrm{C}-2 / \mathrm{G}-3 / \\
\mathrm{F}-8\end{array}$ & & & & 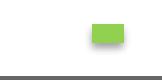 & 口 & - & \\
\hline 11 & $\begin{array}{c}E-1 / E-2 / \\
F-8\end{array}$ & & & & & & & \\
\hline 12 & $\mathrm{G}-2 / \mathrm{H}-3$ & $\square$ & $\square$ & $\square$ & $\square$ & 口 & E & $\square$ \\
\hline 13 & $\begin{array}{l}\text { C-2/ D-1/ F- } \\
3 / \mathrm{H}-6\end{array}$ & & & & & & & \\
\hline 14 & $\begin{array}{l}\text { B-1/ F-3/ F- } \\
8 / \mathrm{G}-2\end{array}$ & & & & & & - & \\
\hline 15 & $\begin{array}{l}\text { D-1/E-2/F- } \\
3 / F-5\end{array}$ & $\theta$ & 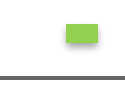 & & $\square$ & 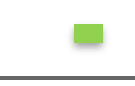 & 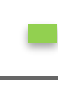 & 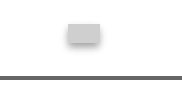 \\
\hline 16 & $\begin{array}{l}E-1 / F-1 / F- \\
3 / F-5 / F-8\end{array}$ & 口 & & & & E & E & $\square$ \\
\hline 17 & $\mathrm{~F}-1 / \mathrm{F}-5$ & $\square$ & $\square$ & 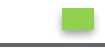 & + & $\square$ & $\square$ & E \\
\hline 18 & $\begin{array}{l}A-3 / F-3 / F- \\
5 / F-8\end{array}$ & & & & & & & \\
\hline 19 & F-6 & E & $\square$ & 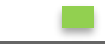 & 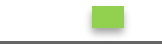 & $\square$ & L & E \\
\hline 20 & $\mathrm{~F}-5 / \mathrm{H}-4$ & - & $\square$ & $\square$ & + & $\square$ & $\square$ & 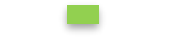 \\
\hline
\end{tabular}


A partir da leitura das tabelas anteriores, foram gerados gráficos para facilitar a compreensão dos resultados. A Figura 1 apresenta o comparativo entre as condições das três categorias:

Figura 1 - Gráfico sintético das três categorias

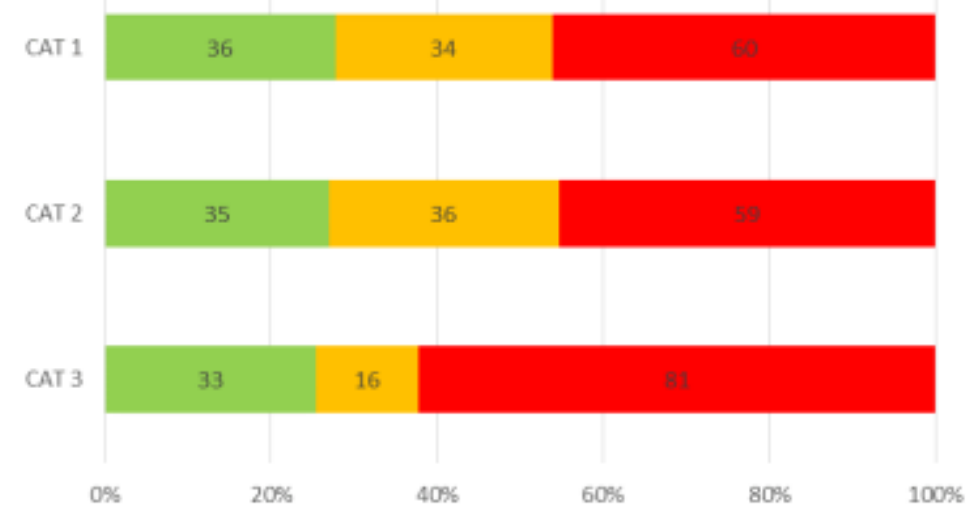

Fonte: Os autores.

A Figura 1 revela, de forma geral, a existência de deficiências relativas à segurança contra incêndio nos projetos analisados, já que em ambas as categorias o índice de condições negativas supera o das demais condições, chegando a ser maior que a soma das condições positivas e intermediárias na Categoria 3.

A quantidade de condições positivas se altera nas três categorias. Logo, pode-se inferir que o atendimento às leis (Categoria 1) não é requisito obrigatório para medir a compreensão do aluno (Categoria 3).

É notória a discrepância de condições negativas entre as categorias, mostrando que o conhecimento dos alunos em questão é frágil, ainda que o seu projeto atenda às leis ou tenha falhas leves.

A Figura 2 expõe as condições gerais de cada lei:

Figura 2 - Gráfico sintético por Norma Técnica

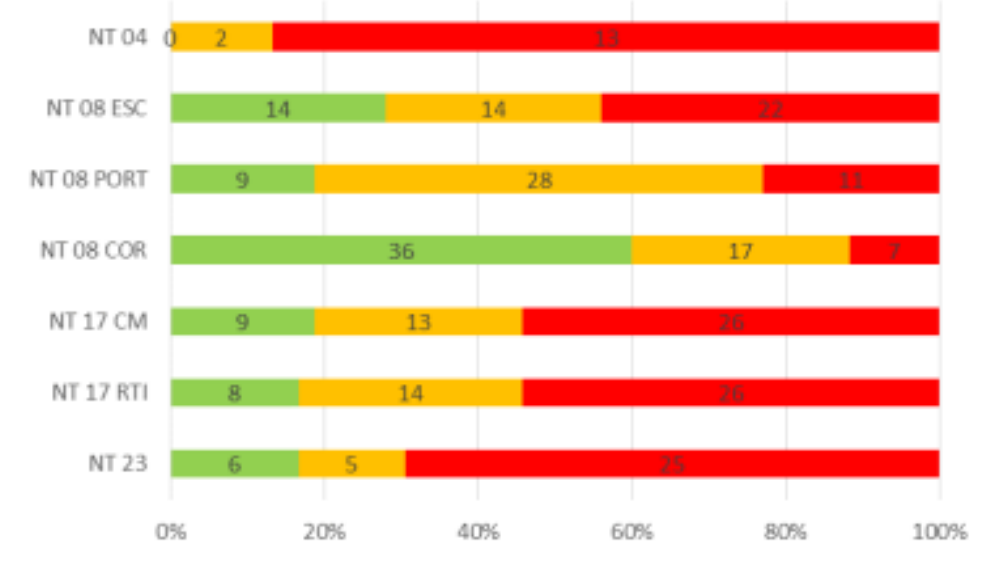

Fonte: Os autores.

É possível notar que a NT 04 (TOCANTINS, 2007b), referente à acesso de Viaturas, é a lei com maior quantidade de erros, seguida das Normas Técnicas 23, de Central de Gás (TOCANTINS, 2007e), e 17, de Sistema de Hidrantes (TOCANTINS, 2007d), ambas de instalações prediais, enquanto que os três itens da NT 08 (TOCANTINS, 2007c), 
corredores, portas e escadas, são aqueles que possuem a menor quantidade dessas condições negativas, que ainda sim são numerosas.

A Figura 3 mostra os erros mais recorrentes nos projetos, sendo possível observar que a porcentagem de trabalhos que preveem as medidas de forma correta é muito pequena, com exceção dos corredores, que ultrapassa $60 \%$ de acerto.

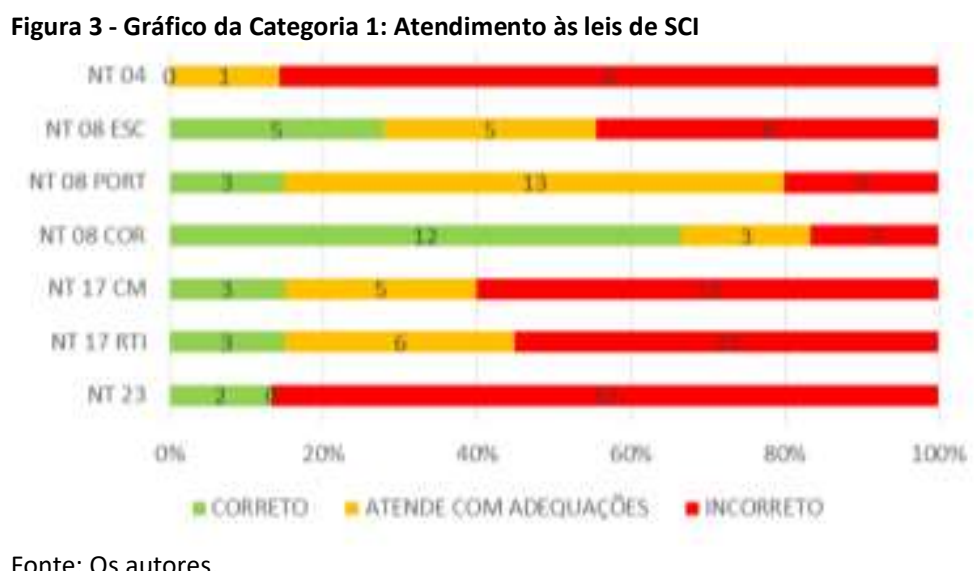

Fonte: Os autores.

Em relação à NT 04 (TOCANTINS, 2007b), nenhum trabalho obteve êxito, já que em nenhum caso o acesso de viaturas foi previsto, quando necessário.

A Figura 4 diz respeito ao comprometimento da arquitetura devido às falhas encontradas. Sua leitura revela que é grande a quantidade de falhas graves nos projetos, sendo que apenas a NT 08 (TOCANTINS, 2007C) - Corredores - possui condição positiva maior do que a intermediária e a negativa. Com exceção da NT 08 (TOCANTINS, 2007c) - Portas, todas as outras medidas possuem mais falhas graves do que leves.

Para se adequar à NT 04 (TOCANTINS, 2007b), aproximadamente $87 \%$ dos projetos sofreriam alterações em sua implantação. As medidas com menor porcentagem de falhas graves são as relacionadas às saídas de emergência: corredores, portas e escadas.

Figura 4 - Gráfico da Categoria 2: Comprometimento da Arquitetura

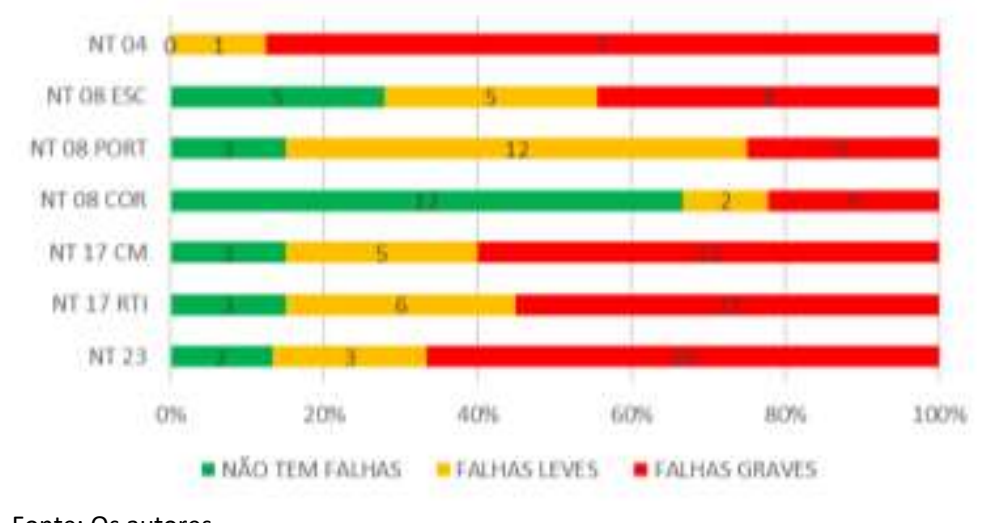

Fonte: Os autores.

A partir da leitura da

Figura 5, nota-se a falta de conhecimento das medidas de segurança contra incêndio por parte dos alunos, chegando a ser preocupante no caso da NT 04 - Acesso de viaturas (TOCANTINS, 2007b). 
Figura 5 - Gráfico da Categoria 3: Conceito de segurança

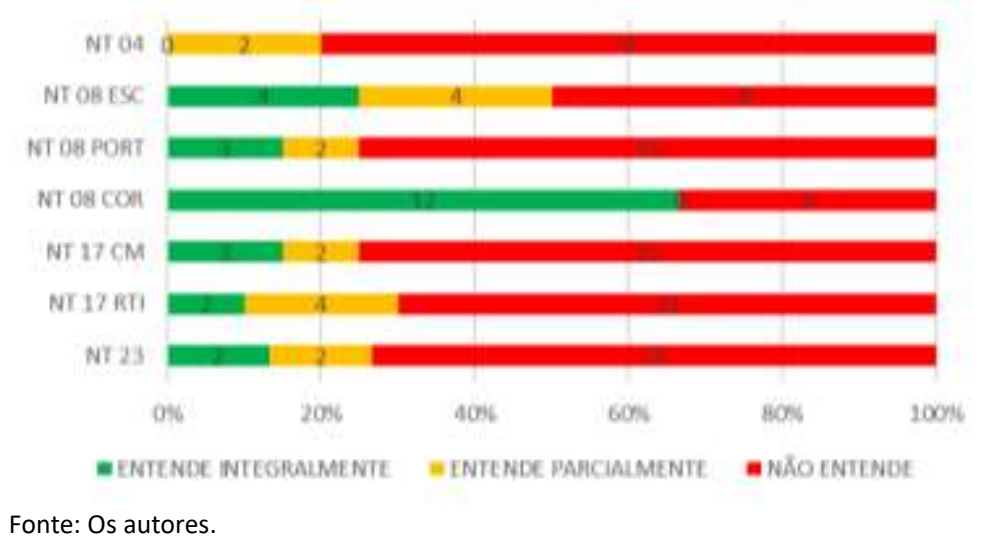

É possível que o resultado da NT 08 (TOCANTINS, 2007C) - Corredores - seja um falso positivo. Isto porque não há como ter certeza se as grandes dimensões de alguns corredores foi algo propositivo pelo próprio partido arquitetônico ou se o aluno o superdimensionou para evitar falhas.

\section{Conclusão}

O desconhecimento da legislação de segurança contra incêndio pode implicar em alterações que causam danos aos projetos arquitetônicos, já que pode descaracterizar a proposta inicial pensada pelo arquiteto. O curso de Arquitetura e Urbanismo da Instituição investigada pôde ser diagnosticado com uma deficiência no ensino da SCl. Entretanto, essa Instituição não é a única instituição de ensino superior do Brasil com esse problema. De acordo com os resultados da pesquisa de Negrisolo (2011), o ensino da $\mathrm{SCl}$ não é satisfatório na maior parte dos cursos de arquitetura no Brasil.

O curso não apresenta disciplina específica de Segurança Contra Incêndio e, de acordo com a análise do Projeto Pedagógico do Curso, são feitas poucas abordagens e referências sobre o tema nas disciplinas de projeto e instalações prediais. Na análise realizada nos Trabalhos de Conclusão de Curso (TCC), constatou-se que a maioria dos alunos formandos desconhecem a legislação de incêndio, já que não inserem as medidas de segurança contra incêndio em seus projetos. Com base nos resultados da análise dos TCC, identificou-se que os erros mais recorrentes nos projetos são aqueles ligados às instalações prediais e à implantação dos edifícios. Por isso, é necessário eliminar a ideia de que as instalações prediais não estão associadas à concepção arquitetônica, e que o arquiteto deve pensar em todo o conjunto que materializa o edifício, com os vários sistemas que o compõe.

Tendo em vista os problemas no ensino da segurança contra incêndio detectados no Curso de Arquitetura e Urbanismo da Instituição investigada, é possível inferir que os alunos não iniciam a vida profissional totalmente aptos, uma vez que a falta de conhecimento da legislação de incêndio pode levar a graves consequências, como falta de compatibilidade entre projetos, descaracterização do projeto e soluções arquitetônicas inadequadas para a segurança do edifício e de seus ocupantes. A exigência que a Lei Federal 13.425/17 (BRASIL, 2017) traz é um passo inicial para a mudança. Entretanto, essa exigência não deve ser cumprida apenas por se tratar de uma obrigação. As IES devem compreender que a falta ou a insuficiência do ensino da $\mathrm{SCl}$ nos cursos de arquitetura pode prejudicar a eficiência da segurança contra incêndio das edificações. Com isso, surge uma expectativa de que o estudo realizado possa contribuir para a qualidade no ensino dos cursos de Arquitetura e Urbanismo do Brasil, o que, 
consequentemente, contribuirá no desenvolvimento profissional dos arquitetos e na segurança das edificações.

\section{Referências}

ABNT - ASSOCIAÇÃO BRASILEIRA DE NORMAS TÉCNICAS. NBR 9077: Saída de Emergência em Edifícios: Procedimento. Rio de Janeiro, 1993.

BRAGA, Marcela Falcão. Ferramenta de análise de medidas de Segurança Contra Incêndio em projetos de arquitetura aplicada ao ensino dos Cursos de Arquitetura e Urbanismo. 2018. 150 p. Dissertação (Mestrado em Arquitetura e Urbanismo) - Faculdade de Arquitetura e Urbanismo. Universidade de Brasília. Brasília, 2018

BRASIL. Lei Federal 13.425, de 30 de março de 2017. Estabelece diretrizes gerais sobre medidas de prevenção e combate a incêndio e a desastres em estabelecimentos, edificações e áreas de reunião de público; altera as Leis nº 8.078, de 11 de setembro de 1990, e 10.406, de 10 de janeiro de 2002 - Código Civil; e dá outras providências. Brasília, 2017.

BRENTANO, Telmo. A proteção contra incêndios no projeto de edificações. 3. ed. Porto Alegre: Edição do autor, 2015.

EASTMAN, Chuck. 2014. Manual de BIM: um guia de modelagem da informação da construção para arquitetos, engenheiros, gerentes, construtores e incorporadores. Porto Alegre: Bookman, 2014. p. 483.

KATER, Marcel; RUSCHEL, Regina C. Avaliando a aplicabilidade de BIM para a verificação da norma de segurança contra incêndio em projeto de habitação multifamiliar. In: ENCONTRO NACIONAL DE TECNOLOGIA DO AMBIENTE CONSTRUÍDO, 15. 2014. Anais [...]. Maceió: ANTAC/AL, 2014. p. 2821-2831.

NEGRISOLO, Walter. Arquitetando a segurança contra incêndio. 2011. 415 f. Tese (em Tecnologia da Arquitetura) Faculdade de Arquitetura e Urbanismo. Universidade de São Paulo, São Paulo, 2011.

ONO, Rosária. Parâmetros para garantia da qualidade do projeto de segurança contra incêndio em edifícios altos. Ambiente Construído, v. 7, p. 97-113, 2007.

ONO, Rosária; SILVA, Valdir; VARGAS, Mauri. Prevenção contra incêndio e o projeto de arquitetura. 1 ed. Rio de janeiro: IABR/CBCA, 2010.

ONO, Rosária. Especialista em segurança contra incêndio fala sobre o papel do arquiteto na concepção de edifícios acessíveis. Arquitetura preventiva. Revista Téchne, São Paulo, ed 198, set. 2013. Entrevista concedida a Renato Faria e Ana Sachs. Disponível em: http://techne17.pini.com.br/engenharia-civil/198/artig0296317-2.aspx. Acesso em: 05 jan. 2018.

SEITO, Alexandre, et al. A segurança contra incêndio no Brasil. 1 ed. São Paulo: Projeto Editora, 2008.

TOCANTINS. Lei Estadual $\mathbf{n}^{\circ}$ 1787, de 15 de maio de 2007. Dispõe sobre a Segurança contra Incêndio e Pânico em edificações e áreas de risco no Estado do Tocantins. Diário Oficial do Estado do Tocantins, nº 2407, Palmas, Tocantins, 2007a.

TOCANTINS. Norma Técnica ${ }^{\circ}$ 04. Acesso de viaturas nas edificações, locais de aglomeração de público e áreas de risco. Suplemento do Diário Oficial do Estado do Tocantins, n² 2499, Palmas, Tocantins, 2007b.

TOCANTINS. Norma Técnica $\mathbf{n}^{\circ}$ 08. Saídas de emergência em edificações. Suplemento do Diário Oficial do Estado do Tocantins, $n^{\circ}$ 2499, Palmas, Tocantins, 2007c.

TOCANTINS. Norma Técnica $\mathbf{n}^{\circ}$ 17. Sistemas de hidrantes para combate a incêndio. Suplemento do Diário Oficial do Estado do Tocantins, ${ }^{\circ} 2499$, Palmas, Tocantins, 2007d. 
TOCANTINS. Norma Técnica n $^{23}$. Manipulação, armazenamento, comercialização e utilização de gás liquefeito de petróleo - GLP. Suplemento do Diário Oficial do Estado do Tocantins, n²499, Palmas, Tocantins, $2007 e$.

TOCANTINS. Norma Técnica $\mathbf{n}^{\circ}$ 24. Dimensionamento de Lotação de Saídas de Emergência em Recintos Esportivos e de Espetáculos Artístico-Culturais. Suplemento do Diário Oficial do Estado do Tocantins, $n^{\circ} 2499$, Palmas, Tocantins, 2007f.

TOCANTINS. Norma Técnica $\mathbf{n}^{\circ}$ 29. Cobertura de Sapé, Piaçava e Similares. Suplemento do Diário Oficial do Estado do Tocantins, $n^{\circ}$ 2499, Palmas, Tocantins, 2007g.

\section{${ }_{1}^{1}$ Marcela Falcão Braga 1}

Arquiteta e Urbanista. Mestre em Arquitetura e Urbanismo. Professora do Curso Técnico de Design de Interiores da União Metropolitana de Educação e Cultura (UNIME). Endereço postal: Rua Rubem de Almeida Machado, 21, Lauro de Freitas, BA, Brasil, 42702-240

\section{${ }^{2}$ Ivan Manoel Rezende do Valle}

Arquiteto e Urbanista. Doutorado em Engenharia Civil. Professor Associado da FAU UnB. Endereço postal: SQS 204, bloco D, apto 304, Brasília, DF, Brasil, 70234-040

\section{Cláudia Maria Miranda Alencar Rocha}

Arquiteta e Urbanista. Mestre em Arquitetura e Urbanismo. Professora Assistente do Curso de Arquitetura e Urbanismo da UFT. Endereço postal: 1004 Sul, alameda 13, n 67, Palmas, TO, Brasil, 77023-524 